\title{
The Production of Spores by Penicillium notatum
}

\author{
By MARY C. FRANK, C. T. CALAM AND P. H. GREGORY \\ Imperial Chemical Industries Ltd., Biological Laboratories, Manchester
}

SUMMARY: Penicillium notatum gives high yields of spores on media containing carbohydrates, ammonia and an organic acid such as citric, tartaric, or succinic acid. The media are similar to those which are good for the production of penicillin, but the choice of organic acids is less restricted.

Of physical factors influencing the yield of spores the most interesting was variation in the volume of medium. Within certain limits the number of spores produced depended almost entirely on the volume of the medium and not on the surface area; i.e. the yield of spores/unit area depended on the depth of the medium. An increase in the concentration of metabolites above normal level did not greatly increase the yield of spores, and the addition of further nutrients to a previously used medium gave only a small second crop. The production of spores therefore appeared to be limited by the accumulation of toxic substances in the medium.

An important step in the production of penicillin is the preparation of the spore suspension of Penicillium notatum to be used as inoculum, and several groups of workers have already described media and conditions of growth which yield large numbers of spores (Moyer \& Coghill, 1946; Gailey, Stefaniak, Olsen \& Johnson, 1946). In the course of our work on penicillin it was desired to extend our knowledge of the factors governing the production of spores by $\boldsymbol{P}$. notatum, in order to obtain the best results in large-scale work. This paper reports the results of investigations on methods for the growth and recovery of large numbers of spores, and on the effects on spore production of the composition of medium, temperature of incubation and the volume and surface area of the medium.

\section{EXPERIMENTAL}

\section{Methods}

Strain. The strain of $\boldsymbol{P}$. notatum used was that used in these laboratories for the production of penicillin by surface culture. It was selected from the well-known Peoria strain, N.R.R.L. 1249 B21, and designated by us $P$. notatum M2.

Conditions of growth. To ensure reproducible results the spores must be grown under standardized conditions, removed completely from the medium and counted by a reliable method. In our experiments we secured the necessary conditions by a 'roll-culture' technique suggested to us by our colleague Dr A. Parker, followed by counting the spores in a haemocytometer. For this purpose $250 \mathrm{ml}$. quantities of medium were placed in $40 \mathrm{oz}$. milk bottles, $4 \%$ agar added and the bottles plugged and autoclaved. The bottles were allowed to cool to $40-50^{\circ}$ and the agar set on the walls in an even layer by careful rotation under a stream of cold water. After testing for sterility by incubation for 3-4 days at $23-24^{\circ}$, the bottles were inoculated with $2 \mathrm{ml}$. of 
a suspension containing $5 \times 10^{7}$ spores $/ \mathrm{ml}$, carefully rotated to distribute the spores over the surface, and then incubated in an upright position in a constanttemperature room at $23-24^{\circ}$.

\section{Counting of spore suspensions}

(a) Direct method. After incubation of the cultures the spores were harvested by adding about 50 glass balls $(c .0 .5 \mathrm{~cm}$. in diameter) and $50 \mathrm{ml}$. water containing $0 \cdot 1 \%(\mathrm{v} / \mathrm{v})$ Calsolene Oil H.S. (Imperial Chemical Industries Ltd., Dyestuffs Division) and then rotating the bottles mechanically at 100 r.p.m. until all the spores had been brought into suspension, as determined by inspection. After suitable dilution the spores were counted in a haemocytometer. Eighty small squares $\left(\frac{1}{400} \mathrm{~mm} .^{2}, \frac{1}{10} \mathrm{~mm}\right.$. thick) were counted, and these usually included about 200 spores. An experiment was carried out to ascertain the numbers of bottles and counts that should be used to obtain repeatable results. In the experiment three bottles were treated in an identical fashion, four similar dilutions were made from each bottle, and four counts made on each dilution (Table 1).

Table 1. Counting of spore suspensions from three bottles of medium

$$
\text { (Medium: glycerol + molasses + peptone agar.) }
$$

The spores were suspended in $50 \mathrm{ml}$. of Calsolene oil-water and diluted 1/100; $80 \frac{1}{400} \mathrm{sq} . \mathrm{mm}$. haemocytometer squares were counted.

\begin{tabular}{|c|c|c|c|c|c|c|}
\hline \multirow{2}{*}{$\begin{array}{c}\text { Bottle } \\
\text { no. }\end{array}$} & & \multicolumn{4}{|c|}{ Counts of dilution no. } & \multirow{2}{*}{$\begin{array}{c}\text { Means } \\
\text { per } \\
\text { bottle }\end{array}$} \\
\hline & & $\mathbf{1}$ & 2 & 3 & 4 & \\
\hline \multirow[t]{5}{*}{1} & & 275 & 315 & 206 & 218 & \\
\hline & & 265 & 297 & 224 & 226 & \\
\hline & & 319 & 392 & 203 & 191 & \\
\hline & & 301 & 290 & 239 & 219 & \\
\hline & Means & 290 & 323 & 228 & 213 & 261 \\
\hline \multirow[t]{5}{*}{2} & & 325 & 248 & 337 & 354 & \\
\hline & & 324 & 271 & 318 & 298 & \\
\hline & & 362 & 270 & 281 & 203 & \\
\hline & & 245 & 212 & 295 & 211 & \\
\hline & Means & 314 & 250 & 308 & 266 & 285 \\
\hline \multirow[t]{5}{*}{$\mathbf{3}$} & & 270 & 257 & 263 & 325 & \\
\hline & & 280 & 297 & 288 & 275 & \\
\hline & & 324 & 240 & 240 & 224 & \\
\hline & & 244 & 256 & 256 & 230 & \\
\hline & Means & 279 & 262 & 262 & 263 & 267 \\
\hline
\end{tabular}

There was no significant variation between bottles, but two samples out of one bottle gave significantly lower results than the others. The overall standard deviation between repeat counts from the same sample was $16 \%$, which is greater than the theoretical figure of $6 \%$ for slide counting methods with mean counts of 250-300. It was concluded from the analysis of the data that to detect differences of 15,30 and $100 \%$ from a given average value 5, 2 and 1 
counts respectively were required. However, owing to the possibility of an occasional abnormal sample or bottle, at least two bottles should be sampled in each case, and more than one sample from each bottle should be diluted and counted.

In each of the experiments described below, three or four bottles were inoculated, three samples were taken from the spore suspension prepared from one bottle; the samples were bulked, diluted, and two counts made on the resultant suspension. This procedure was repeated for the other bottles, so that the figures quoted are usually based on at least six counts. The yield of spores was calculated as the number/ml. of medium.

(b) Densitometric method. As an alternative and less laborious method of determining the numbers of spores in suspensions we tried a densitometric method, using a Spekker photometer. This method was suggested to us by our colleague Miss K. M. Wood, who had obtained encouraging results, using the M2 strain of $\boldsymbol{P}$. notatum and the glycerol-molasses medium. We examined suspensions grown on the eight media referred to in Table 4. When the log of the concentration of spores was plotted against the log of the extinction coefficient straight lines were obtained which were parallel and lay very close together when two bottles of the same medium were taken. With different media, however, the pairs of lines were widely separated and were not parallel. These results show that although the method may be valuable for routine purposes it is unsuitable when a variety of media are being tested. The differences which we encountered could not be removed by using filters to compensate for difference in the colour of the spores or the liquid in which they were suspended.

\section{RESULTS}

\section{Media containing glycerol, molasses, and peptone}

The medium used was a glycerol molasses peptone medium based on that of Moyer \& Coghill (1946), which preliminary tests had shown to be as good as any. The modification used by us had the following formula (figures show $\%(w / v)$ throughout): glycerol, 1; molasses, 1; peptone (bacteriological, Evans Medical Supplies, Ltd.), 0.5; NaCl, 0.5; $\mathrm{KH}_{2} \mathrm{PO}_{4}, 0.006 ; \mathrm{MgSO}_{4} .7 \mathrm{H}_{2} \mathrm{O}$, $0.05 ; \mathrm{FeSO}_{4} .7 \mathrm{H}_{2} \mathrm{O}, 0.0012 ; \mathrm{MnSO}_{4} .4 \mathrm{H}_{2} \mathrm{O}, 0.004 ; \mathrm{CuSO}_{4} .5 \mathrm{H}_{2} \mathrm{O}, 0.004$. This medium was made up with tap water and adjusted to $\mathrm{pH} 6.5$ with $\mathrm{NaOH}$ and solidified with $4 \%$ agar.

Preliminary tests with 25 different media showed that this recipe gave the highest yield of spores. Some of these media contained various vegetable extracts only, whilst others consisted of Czapek-Dox solution to which the extracts were added. The best yielded 20-80 million spores $/ \mathrm{ml}$. medium. The glycerol-molasses recipe usually yielded 300-500 million spores $/ \mathrm{ml}$. medium. Subsequently a number of synthetic media were tested, and some of these gave similar yields.

The optimal concentrations of salts and other constituents in glycerol molasses peptone media were tested by a simple factorial experiment in which 
media were made up containing the salts at 50,100 and $200 \%$ of the usual concentrations, and glycerol molasses and peptone in the same proportions (Table 2).

\section{Table 2. Production of spores with different concentrations of ingredients}

The yields are based on counts made on the 8th day. Counts made on the 3rd and 10th days gave similar results.

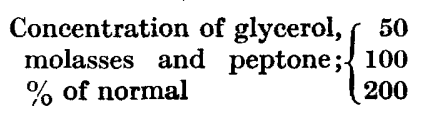

\begin{tabular}{|c|c|c|}
\hline \multicolumn{3}{|c|}{ Concentration of salts, $\%$ of normal } \\
\hline 50 & 100 & 200 \\
\hline \multicolumn{3}{|c|}{ Yield of spores (millions/ml. medium) } \\
\hline 248 & 262 & 226 \\
\hline 218 & 384 & 326 \\
\hline 290 & 334 & 398 \\
\hline
\end{tabular}

The best results were obtained with the two higher concentrations of ingredients. The difference between the yields given by these concentrations was too small to be detected in this experiment.

In another experiment two levels each of glycerol molasses peptone, volume of medium, and concentration of agar were used (Table 3).

Table 3. Production of spores with different concentrations of nutrients and agar and volume of medium



The results show highest production of spores with normal concentration of nutrients and $300 \mathrm{ml}$. medium. The increase in the concentration of agar decreased the yield of spores. Counts made on the 4th day showed similar effects. In other experiments an increase in the.concentration of the medium above the normal usually produced small increases in the yield of spores.

\section{Synthetic media}

Although the media so far described give high yields of spores a brief study of synthetic media was made, since they might be more reliable. Gailey et al. (1946) concluded that, of the substances in the glycerol molasses peptone medium, the peptone was the most important for the production of spores.

In an initial experiment spore production was measured on a basal medium containing the salts as used in the glycerol molasses peptone medium with the addition of sucrose $(0.5 \%)$, molasses $(1 \%)$, peptone $(0.5 \%)$, aqueous ammonia sp.gr. $0.880(0.33 \%)$, glycerol $(0.5 \%)$, acetic acid $(0.75 \%)($ all $\%$ w/v). The combinations used, a half-replicate of the full factorial design, and the yields, 
are shown in Table 4. This type of experimental design is based on the work of Finney (1945). Although a half-replicate is not usually recommended for so few factors it was considered worth while in this case as the experiment was only exploratory, and by this means a representative set of treatments was obtained.

\section{Table 4. Production of spores on synthetic media}

The treatment combinations tested and the yields of spores are shown in the upper lines, $a_{0}$ indicating the presence of sucrose, $a_{1}$ the presence of molasses, $b$ the presence of peptone, etc. In the analysis the combinations are shown diagrammatically, together with a summary of the mean effects produced by each main factor. 'Mean sucrose' represents the mean yields of all media containing sucrose, 'mean molasses' the mean of all with molasses, etc.

$$
\begin{aligned}
& \text { Combination of factors } \\
& \text { Spores (millions/ml. medium) } \\
& \text { incubated } 10 \text { days }
\end{aligned}
$$

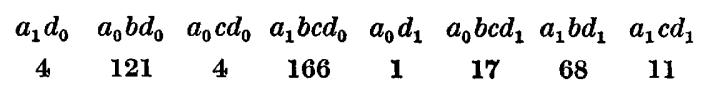

Mean yields of spores (millions/ml. medium)

$\begin{array}{lr}\text { Mean sucrose }\left(a_{0}\right) & 36 \\ \text { Mean molasses }\left(a_{1}\right) & 62 \\ \text { Mean without peptone }(-) & 5 \\ \text { Mean with peptone }(b) & 93 \\ \text { Mean without ammonia }(-) & 49 \\ \text { Mean with ammonia }(c) & 49 \\ \text { Mean glycerol }\left(d_{0}\right) & 74 \\ \text { Mean acetic acid }\left(d_{1}\right) & 24\end{array}$

The largest effect was due to peptone, which markedly increased spore production. Glycerol was superior to acetic acid, which was the next factor in order of importance. No reliable conclusions could be drawn as to the comparison of sucrose and molasses and the effect of ammonia. The indications were that molasses might be superior to sucrose and that ammonia had no effect.

This experiment confirmed the importance of peptone as a factor for sporulation and also showed that glycerol was superior to acetic acid. In subsequent experiments glycerol was therefore added to all media.

Peptone is rich in amino-acids, which probably act as sources of nitrogen and carbon. It was thought that the peptone might be replaced by a suitable mixture of ammonia and a carboxylic acid. This possibility was suggested by the behaviour of synthetic media used for penicillin production, which were 
found to be greatly improved by the addition of $0.5-1.5 \%(w / v)$ of citric acid. Media were therefore made up to contain $0.75 \%(w / v)$ of various organic acids and the production of spores was measured. A parallel set of cultures was prepared with slightly different basal medium and the production of penicillin measured. The results of this experiment are shown in Table 5. The

\section{Table 5. Production of spores and penicillin on synthetic media}

The basal medium contained lactose $2 \%(\mathrm{w} / \mathrm{v})$, glycerol $1 \%(\mathrm{v} / \mathrm{v}), \mathrm{NaCl} 1 \%(\mathrm{w} / \mathrm{v})$, $\left(\mathrm{NH}_{4}\right)_{2} \mathrm{SO}_{4} 0.5 \%$ (w/v), salt mixture $1 \%(\mathrm{v} / \mathrm{v}), \mathrm{KH}_{2} \mathrm{PO}_{4} 0.1 \%(\mathrm{w} / \mathrm{v}), \mathrm{NaF} 0.001 \%(\mathrm{w} / \mathrm{v})$; with the addition of glucose $2 \%(w / v)$ for sporulation or glucose $0.5 \%(w / v)$ and phenylacetic acid $0.05 \%(\mathrm{w} / \mathrm{v})$ for penicillin production. All media were adjusted to $\mathrm{pH} 5 \cdot 7-6 \cdot 0$ with $\mathrm{KOH}$. The salt mixture contained $\mathrm{MgSO}_{4} \cdot 7 \mathrm{H}_{2} \mathrm{O}, 50 \mathrm{~g}$. ; $\mathrm{FeSO}_{4} \cdot 7 \mathrm{H}_{2} \mathrm{O}, 2 \mathrm{~g}$.; $\mathrm{MnSO}_{4} \cdot 4 \mathrm{H}_{2} \mathrm{O}$, 1 g.; $\mathrm{ZnSO}_{4} .5 \mathrm{H}_{2} \mathrm{O}, 1$ g.; $\mathrm{CuSO}_{4} .5 \mathrm{H}_{2} \mathrm{O}, 1 \mathrm{~g}$.; $\mathrm{Co}\left(\mathrm{NO}_{3}\right)_{2} .6 \mathrm{H}_{2} \mathrm{O}, 2 \mathrm{~g}$.; water, $1 \mathrm{l}$.

$\begin{array}{lcc}\text { Acid added } & \begin{array}{c}\text { Spores } \\ (0 \cdot 75 \%)\end{array} & \begin{array}{c}\text { Penicillin } \\ \text { units } / \mathrm{ml} .\end{array} \\ \text { Nil } & \text { (10 days) } \\ \text { Citric } & 0 & 0 \\ \text { Lactic } & 246 & 53 \\ \text { Succinic } & 154 & 0 \\ \text { Tartaric } & 282 & 42 \\ \text { Glycollic } & 316 & 58 \\ \text { Acetic } & 178 & \text { Trace } \\ \text { Oxalic } & 242 & 0 \\ \text { Malic } & 294 & 0 \\ & 224 & 38\end{array}$

basal medium is seen to be not the most suitable for the production of penicillin and the titres recorded were relatively low. However, it is interesting that citric, succinic, tartaric and malic acids gave good yields of spores and penicillin while other acids gave many spores but no penicillin. There was in this series no instance in which there was a good yield of penicillin and a poor yield of spores. In the absence of an organic acid only mycelial growth occurred during the rather short incubation period.

The results of other experiments which illustrate the high spore-yielding properties of synthetic media are illustrated by Table 6 . Although the addition

Table 6. Production of spores on synthetic media

Basic medium same as for Table 4, incubated 6 days.

\begin{tabular}{|c|c|c|}
\hline No. & Addition ( $\%$ ) & $\begin{array}{l}\text { Spores, millions } / \mathrm{ml} \text {. } \\
\text { medium, after } 6 \text { days }\end{array}$ \\
\hline 1 & Nil & 4 \\
\hline 2 & Citric acid 0.5 & 140 \\
\hline 8 & Citric acid $1 \cdot 0$ & $\begin{array}{l}440 \\
362 \text { (when repeated) }\end{array}$ \\
\hline 4 & Citric acid 0.5 , acetic acid 0.25 & 372 \\
\hline 5 & Glycerol $1 \cdot 0$, citric acid 0.5 & $\begin{array}{l}592 \\
280 \text { (when repeated) }\end{array}$ \\
\hline 6 & Glycerol $0 \cdot 5$, lactic acid $1 \cdot 0$ & 230 \\
\hline 7 & $\begin{array}{l}\text { Glycerol } 0 \cdot 5 \text {, citric acid } 1 \cdot 0,\left(\mathrm{NH}_{4}\right)_{2} \mathrm{SO}_{4} \\
0.25\end{array}$ & 258 \\
\hline 8 & $\left(\mathrm{NH}_{4}\right)_{2} \mathrm{SO}_{4} 0.25$, lactic acid 0.5 & 6 \\
\hline Control & Glycerol + molasses + peptone agar & 396 \\
\hline
\end{tabular}


of more glycerol had an appreciable effect, the addition of citric acid gave the most striking results. The yields of spores seemed to be about equal to those obtained with the glycerol molasses peptone medium. These synthetic media contain a high concentration of carbohydrate and of carbon in the form of an organic acid; the presence of organic nitrogen seemed relatively unimportant. The best media for the production of spores were not unlike those which are suitable for the production of penicillin, but for the latter purpose the range of organic acids is more restricted.

The mechanism whereby the addition of organic acids increases the yield of spores remains unknown. Several authors have shown that the dry weight of mycelium produced by Phycomyces blakesleeanus is increased by addition of organic acids to the medium. Thus Leonian \& Lilly (1940) concluded that the addition of organic acids facilitated the utilization of unfavourable nitrogen sources such as ammonium nitrate. Burkholder \& McVeigh (1940), reporting similar results, suggested that these acids might be acting as a supplementary source of carbon. They also showed that the addition of organic acids influenced the type of sporangia which were produced.

\section{Effect of different cultural conditions on spore production}

The following experiments were carried out in the glycerol molasses peptone medium described above. Small-scale trials showed that spore production was best at $23-24^{\circ}$. The yields of spores were less at 20 or $28^{\circ}$, although at $28^{\circ}$ growth and colour were apparently excellent. For example, after 6 days the spore yields were 320 and $80 \mathrm{million} / \mathrm{ml}$. medium at 24 and $28^{\circ}$, respectively. The importance of making direct counts instead of judging by appearance was emphasized by this experiment.

Inoculation with $2 \mathrm{ml}$. of spore suspension, as described above, was found to be satisfactory. With $8 \mathrm{ml}$. of the same suspension spore production seemed rather less; this, however, was not studied in detail. The number of spores present was usually greatest after 4-5 days, cover by mycelium being attained after 1-2 days and a green colour appearing after 3 days. Table 7, which shows the results of an experiment on the effect of volume and depth of medium, illustrates this point. In this experiment the production of spores in milk bottles is compared with that in Winchester bottles.

Table 7. Spore production with different volumes of medium in milk bottles (M.B.) and Winchester bottles (Win.)

\begin{tabular}{|c|c|c|c|c|c|c|c|c|c|c|}
\hline $\begin{array}{l}\text { Volume of m } \\
\text { dium (ml.) }\end{array}$ & e- & & & & & & & & & \\
\hline Vessel & $\cdots$ & M.B. & Win. & M.B. & $\begin{array}{l}\text { Win. } \\
\text { ores (n }\end{array}$ & $\begin{array}{l}\text { M.B. } \\
\text { ions/n }\end{array}$ & $\begin{array}{l}\text { Win. } \\
\text { mediu }\end{array}$ & M.B. & Win. & Mean \\
\hline $\begin{array}{c}\text { Days } \\
2\end{array}$ & & 78 & 66 & 21 & 42 & 9 & 24 & 8 & 3 & 31 \\
\hline $\mathbf{2}$ & & 278 & 389 & 415 & 437 & 317 & 217 & 147 & 120 & 290 \\
\hline 4 & & 405 & 326 & 553 & 510 & $\mathbf{3 5 0}$ & 484 & 204 & 304 & 392 \\
\hline 6 & & 473 & 4.57 & 630 & 640 & 435 & 557 & 175 & 447 & 477 \\
\hline 9 & & 362 & 381 & 4.26 & 410 & 383 & 485 & 165 & 278 & 361 \\
\hline
\end{tabular}


It will be noted that the counts were highest on the 4th and 6th days. The marked fall in number of spores by about the 8 th day is characteristic. It may well be due to the germination of some of the spores, either in situ or after falling from the conidiophores, so that they are no longer recognizable as spores; a detailed examination of this point was not made.

\section{Depth of medium}

A preliminary experiment suggested that the production of spores per unit area of medium was roughly proportional to its depth. This effect was somewhat unexpected and does not appear to have been previously reported. A large experiment was therefore set up in order to investigate it further. The same volumes of medium $(75,150,300$ and $650 \mathrm{ml}$.) were used in milk bottles and $80 \mathrm{oz}$. Winchester bottles. The internal dimensions of the latter were approximately $11 \mathrm{~cm}$. diameter by $23 \mathrm{~cm}$. long. As the surface area of a Winchester is about double that of a milk bottle, comparable thicknesses were obtained in three instances. Counts were made on the 2 nd, 3rd, 4th, 6th and 9 th days, there being usually three replicate bottles (Table 7). The mean values for the 4th and 6th days, together with the yield of spores per unit area of medium surface, are given in Table 8.

Table 8. Production of spores on different depths of medium

(All spore counts are in millions.)

\begin{tabular}{|c|c|c|c|c|c|}
\hline $\begin{array}{l}\text { Volume } \\
\text { (ml.) }\end{array}$ & $\begin{array}{l}\text { Depth } \\
\text { (mm.) }\end{array}$ & $\begin{array}{l}\text { Surface area } \\
\left(\mathrm{cm}^{2}\right)\end{array}$ & Spores/bottle & $\begin{array}{l}\text { Spores/ml. } \\
\text { medium }\end{array}$ & $\begin{array}{c}\text { Spores } / \mathrm{cm}^{2} \\
\text { medium surface }\end{array}$ \\
\hline \multicolumn{6}{|c|}{ Milk bottles } \\
\hline 75 & 2 & 410 & 32,500 & 433 & 79 \\
\hline 150 & 4 & 394 & 88,500 & 590 & 224 \\
\hline 300 & 8 & 356 & 118,000 & 393 & 332 \\
\hline 650 & 20 & 248 & 123,500 & 190 & 498 \\
\hline \multicolumn{6}{|c|}{ Winchesters } \\
\hline 75 & 1 & 785 & 29,400 & 392 & 38 \\
\hline 150 & 2 & 774 & 86,500 & 566 & 112 \\
\hline 300 & 4 & 750 & 161,000 & 537 & 214 \\
\hline 650 & 9 & 681 & 242,400 & 373 & 356 \\
\hline
\end{tabular}

The yield of spores lay between 400 and $600 \mathrm{million} / \mathrm{ml}$. of medium under the various conditions tested, except when $650 \mathrm{ml}$. medium were used, with a consequent diminution of the ratio of surface to volume. The production of spores per unit area appears to be fairly directly related to the depth of the medium up to depths of about $8 \mathrm{~mm}$., when there is some falling off (Table 9).

Table 9. Spore production with different depths of medium

$\begin{array}{cccc}\begin{array}{c}\text { Depth of } \\ \text { medium (mm.) }\end{array} & \overbrace{\text { Winchesters }}^{\text {Spores } / \mathrm{cm}^{2} \text { (millions) }} & \text { Milk bottles } & \text { Mean } \\ 1 & 38 & - & 38 \\ 2 & 112 & 79 & 96 \\ 4 & 214 & 224 & 219 \\ 8-9 & 356 & 332 & 344 \\ 20 & - & 498 & 498\end{array}$


The volume of medium is thus more important than surface area in governing spore production. A doubling of surface area (milk bottles to Winchesters) only increases the yield if the depth remains constant, and a similar increase in yield of spores would have been obtained if the larger volume of medium had been put in the milk bottles. With milk bottles, however, the surface area falls off with increasing depth, and the relationship was less marked when the thickness reached $20 \mathrm{~mm}$.

It is interesting to note that the production of penicillin is also influenced by the depth of the medium. Thus with a medium containing corn-steep liquor and lactose in $250 \mathrm{ml}$. conical flasks the peak titres of penicillin were increased, and the yields of penicillin per $\mathrm{cm}^{2}$ of surface with depths of $4,8,16$, and $24 \mathrm{~mm}$. were $45,128,243$ and 250 units respectively, the optimum corresponding to a depth of about $20 \mathrm{~mm}$. The shallower layers reach their highest titres much earlier than the deeper ones.

Factors limiting the production of spores of Penicillium notatum

The association between the depth of medium and number of spores produced per unit area suggested the presence of some factor related to the volume of the medium which controls the production of spores. Possible explanations are (i) that the larger volume of medium in the deeper layers would contain more nutrients and the yield should therefore be greater, (ii) the mould might

Table 10. Spore production on previously used media

Bottles of single or double strength medium were inoculated and incubated 6 days. The spores were removed. In the unmelted set, fresh solutions of glycerol, etc., were added and the bottles rotated until the solution was absorbed. In the others the agar medium was melted, the mycelium removed and the medium reset on the walls.

\begin{tabular}{|c|c|c|c|}
\hline \multirow[b]{2}{*}{ First crop } & & \multicolumn{2}{|c|}{ Spores, millions $/ \mathrm{ml}$. of } \\
\hline & after 6 days & $\begin{array}{c}\text { Single } \\
\text { strength } \\
\text { medium } \\
416\end{array}$ & $\begin{array}{c}\text { Double } \\
\text { strength } \\
\text { medium } \\
470\end{array}$ \\
\hline \multirow{4}{*}{$\begin{array}{r}\text { Second crop } \\
\text { Unmelted }\end{array}$} & \multicolumn{2}{|l|}{ after 4 days } & \\
\hline & No addition & 43 & 56 \\
\hline & With glycerol molasses & 83 & - \\
\hline & $\begin{array}{l}\text { With glycerol molasses } \\
\text { and peptone }\end{array}$ & 24 & 一 \\
\hline \multirow{3}{*}{ Melted } & No addition & 8 & 91 \\
\hline & With glycerol molasses & 79 & - \\
\hline & $\begin{array}{l}\text { With glycerol molasses } \\
\text { and peptone }\end{array}$ & 112 & - \\
\hline
\end{tabular}

produce substances which would accumulate in the medium and thereby prevent growth, and with larger quantities of medium more spores could be produced before the concentration became sufficient to interfere with the process.

The experiments illustrated by Tables 2 and 3 suggest that merely increasing the quantity of nutrients above the normal would not be sufficient to account for the observed effect, for the effect of increasing the concentration of the 
nutrients usually was not as great as that obtained if the volume was doubled. Increasing the salts supplied, either directly or incidentally by increasing the quantity of agar, would be unlikely to account for the observed effect.

Both possibilities were examined by attempts to obtain a second crop of spores from once-used medium. It was found that if the first crop of spores was milled off, further production of spores was only slight; very small yields were also obtained when the medium was melted, the old mycelium removed, the medium resolidified on the walls and reinoculated. Rather larger yields of spores were obtained when more nutrients were added before resolidifying. The rather small size of the second crops appeared to be due to the presence of inhibiting substances. The $\mathrm{pH}$ of used media was found to be in the range of $6 \cdot 0-6 \cdot 5$, which is similar to the original one. The addition of small quantities of acid or alkali did not increase the size of the second crop of spores. These statements are illustrated by a typical experiment recorded in Table 10. 'Melted' and 'unmelted' sets were included in order to find out whether the toxic substances preventing further sporulation were thermolabile. Our results are not conclusive on this point but are sufficient to indicate that heating had little or no effect upon them.

We wish to acknowledge the guidance we have received from Dr O. L. Davies in the planning and analysis of the results of some of the experiments described in this paper.

\section{REFERENCES}

Burkholder, P. R. \& McVergh, I. (1940). Growth of Phycomyces blakesleeanus in relation to varied environmental conditions. Amer. J. Bot. 27, 634.

FinNey, D. J. (1945). The fractional replication of factorial arrangements. Ann. Eugen., Lond., 12, 291.

Gailex, F. B., Stefaniak, J. J., Olsen, B. D. \& Johnson, M. J. (1946). A comparison of penicillin-producing strains of Penicillium notatum-chrysogenum. J. Bact. 52, 192.

Leonian, L. H. \& LiLLy, V. G. (1940). Studies on the nutrition of fungi. VI. Some factors influencing the growth of some thiamine requiring fungi. Amer. J. Bot. $27,18$.

Moyer, A. J. \& Coghrlu, R. D. (1946). Penicillin. VIII. Production of penicillin in surface cultures. J. Bact. 51, 57.

(Received 15 August 1947) 